\title{
Mastoid Osteoma: A Case Report
}

\author{
Mastoid Osteom: Olgu Sunumu
}

Caner Şahin ${ }^{1 *}$

1.Alanya Alaaddin Keykubat Üniversitesi Tıp Fakültesi, Kulak Burun Boğaz Hastalıları AD. Alanya, Türkiye

\section{ABSTRACT}

Osteoma in temporal bone region is a benign osteoblastic lesion that is very rare in literature. Mass lesion can lead to slow-growing hard lesion behind the earwhich can cause to cosmetic problems. The lesion is treated by observation or in cases with surgery. We presented an osteoma in the mastoid segment of the temporal bone in the light of existing literature herein.

Keywords: mastoid, osteoma, temporal bone
Öz

Temporal kemikte osteom literatürde nadiren izlenen bir osteoblastik benign lezyondur. Lezyon kulak arkasında yavaş büyüyen sert, kozmetik sorunlara yol açabilen kitle lezyonuna neden olur. Lezyon takip ya da bazı vakalarda cerrahi olarak tedavi edilir. Vaka takdimimizde temporal kemiğin mastoid segmentinde mevcut osteom literatür eşliğinde sunulmuştur.

Anahtar Kelimeler: mastoid, osteom, temporal kemik

*Sorumlu Yazar: Caner Şahin, Alanya Alaaddin Keykubat Üniversitesi Tıp Fakültesi, Kulak Burun Boğaz Hastalıkları AD. Alanya/Antalya,Türkiye. Tel: +902425106135 Fax: +902425106139 mail: drcaner2001@gmail.com 
$\mathrm{O}$ steom baş boyun bölgesinde frontal ve etmoid sinüslerde, ayrıca dış kulak yolunda izlenebilen osteoblastik mezanşimal tümördür [1]. Yapılan bir çalışmada temporal kemikte osteom \% 66 dış kulak yolunda, \% 21 mastoid kemikte, \% 13 oranında orta kulak boşluğunda izlenmiştir [2]. D1ş kulak yolunda olan osteomlar asemptomatik olabileceği gibi, mastoid kemikte olan osteomlar kozmetik deformiteye yol açarlar. Vaka takdimimizde temporal kemiğin mastoid segmentinde mevcut osteom literatür eşliğinde sunulmuştur.

\section{OLGU SUNUMU}

Kliniğimize, kulak arka kesiminde sert, sabit kitle şikayetleri ile başvuran 52 yaşındaki erkek hastanın, yapılan fizik muayenesinde; kulak zarının intakt ve doğal olduğu, dış kulak yolunun doğal olduğu izlendi. Sol mastoid bölgeye uyan lokalizasyonda sert, fikse yaklaşı $5 \times 5 \mathrm{~cm}$ boyutlarında kitle lezyonu izlendi. Hasta lezyonun 10 yıldır mevcut olduğunu son 5 yıldır yavaş yavaş büyüdüğ̈̈nü ve son 2 yıldır aynı boyutta kaldığı$\mathrm{n} 1$ ifade etti. Hastaya temporal bilgisayarlı tomografi (BT) çekildi.

Hastaya yapılan BT incelemesinde sol temporal kemik mastoid parçasının diş tabulasından dişa doğru uzanan korteksle bağlantılı 21×30x34 mm boyutlarında komşu kemik korteksi ile izodens düzgün konturlu kitle izlendi (Resim 1A, B). Mastoid hücrelerde infiltrasyon, lezyon izlenmedi. Hastaya anamnez, fizik muayene ve radyolojik yöntemler ile mastoid osteom tanısı konuldu, cerrahi tedavi önerildi.

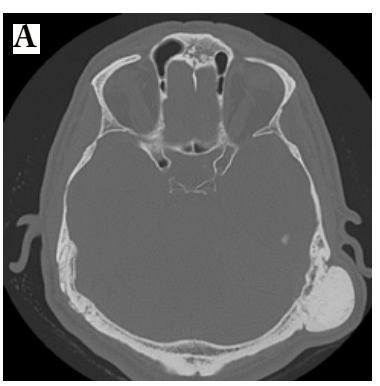

Resim 1. A)Aksiyel plandaki BT görüntüsünde sol temporal kemik mastoid parçasının dış tabulasından dışa doğru uzanan korteksle bağlantılı 21x30x34 mm boyutlarında komşu kemik korteksi ile izodens düzgün konturlu kitle izlenmektedir (Osteom). B) Koronal reforme BT görüntüsünde sol temporal kemikte korteksle izodens lezyon izlenmekte.

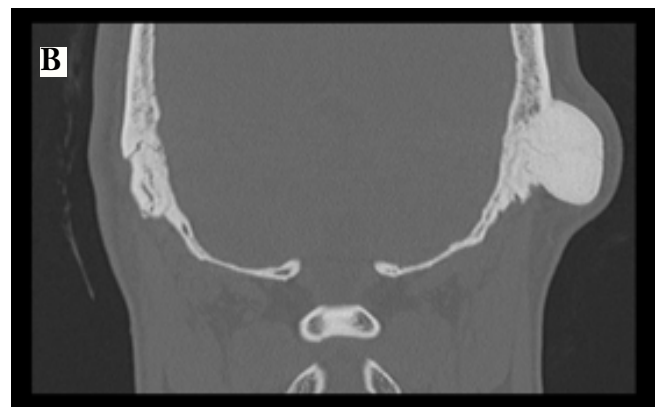

\section{TARTIŞMA}

Osteomlar baş boyun bölgesinde frontal etmoid bölgede, maksiler sinüste, mandibulada nadiren de temporal kemikte izlenir [3, 4]. Temporal kemikte olan osteomlar diş kulak yolunda, orta kulakta, akustik kanalda, petröz apekste ve nadiren mastoid kortekste izlenir [ 5, $6,7]$. Baş boyun bölgesinde olan benin tümörler içerisinde mastoid kemik osteom insidans1 \% 0.1-1 arasında bildirilmiştir [8].

Lezyon Gardner sendromu ile birikte ve non sendromik olarak literatürde bildirilmiştir [9]. Gardner sendoromu haricinde non sendromik vakalar mevcuttur. Hastalığın etyopatogenezinde travma, inflamasyon, metaplazi, cerrahi nedenler suçlanmakla birlikte tam olarak patogenez bilinmemektedir [10].

Mastoid kemik osteomları nadiren $3 \mathrm{~cm}$ üzerine çıkmaktadır $[11,12]$. Genellikle mastoid korteksten d1şar1 olarak büyümektedirler. Lezyon üzerindeki cilt normaldir. Nadiren mastoid osteom iç kulak yoluna, petröz apekse, fasial sinire doğru uzanım gösterir [13]. Hastalık kemik ağırlıklı olduğu için Bilgisayarlı tomografi tanıda önemlidir.

Hastalığın tedavisi hastanın semptomları ve uzanımına bağlıdır. Asemptomatik vakalar takip edilebilmektedir. Hızlı büyüyen vakalarda, fasial sinir ve dış kulak yoluna uzanarak iletim tipi işitme kaybına neden olabilen vakalarda cerrahi tedavi uygulanabilir $[14,15]$. Cerrahi yaklaşımda normal cerrahi sınıra ulaşılana kadar mastoid korteks turlanır ve lezyon vital yapılara dikkat edilerek eksize edilir. Literatürde malign transformasyon bildirilmemiştir [16].

Sonuç olarak bu tür olgularda temporal kemiğin mastoid segmentinde osteoma tanısı akılda tutulmalıdır.

Çıkar Çatışması: Yazar bu yazının hazırlanması ve yayınlanması aşamasında herhangi bir çıkar çakışması olmadığını beyan etmiştir.

Finansman: Yazar bu yazının araştırma ve yazarlık sürecinde herhangi bir finansal destek almadıklarını beyan etmiştir.

\section{KAYNAKLAR}

Arslan HH, Tasli H, Cebeci S, Gerek M. The Management of the Paranasal Sinus Osteomas. J Craniofac Surg. 2017;28(3):741-45

2. Arslan HH, Gökgöz MC, Cebeci S, Taşlı H. Treatment approaches to temporal bone osteomas. Kulak Burun Bogaz Ihtis Derg. 2016; 26(6):342-77

3. Souza PD, Leonhardt FD, Ahumada NG, Abrahão M, Cervantes O. Giant osteoma of the mandible. Braz J Otorhinolaryngol. 2015; 81(1):107-8 
4. Lodha JV, Dabholkar JP, Dhar H. Fronto-ethmoid osteoma: addressing surgical challenges. J Postgrad Med. 2014; 60(2):207-8

5. Tamir SO, Cyna-Gorse F, Sterkers O. Internal auditory canal osteoma: Case report and review of the literature. Ear Nose Throat J. 2015; 94(6): 23-5

6. Toro PC, Castillo AC, Moya Martínez R, Domènech Juan I. Middle ear promontory osteoma. Am J Otolaryngol. 2014; 35(5):626-7

7. Suzuki J, Takata Y, Miyazaki H, Yahata I, Tachibana Y, Kobayashi T, Kawase T, Katori Y Osteoma of the internal auditory canal mimicking vestibular schwannoma: case report and review of 17 recent cases. Tohoku J Exp Med. 2014; 232(1):63-8

8. Pereira Carlos Umberto, de Carvalho Ricardo Wathson Feitosa, de Almeida Annie Merielle Gomes, Dantas Rafaela Nunes. Mastoid osteoma. Consideration on two cases and literature review. Int Arch Otorhinolaryngol Sã Paulo. 2009; 13(3):350-353

9. Boffano P, Bosco GF, Gerbino G. The surgical management of oral and maxillofacia manifestations of Gardner syndrome. J Oral Maxillofac Surg. 2010; 68(10):2549-54

10. Domınguez Perez AD, Rodrıguez Romero R, Domınguez Duran E, Riquelme Montano P, Alcantara Bernal R, Monreal Rodriguez C. The mastoid osteoma, an incidental feature? Acta Otorrinolaringol Esp. 2011; 62: 140-143

11. Parelkar Kartik, Thorawade Vandana, Jagade Mohan, et al. Osteoma of temporal bone a rare case report. Int J Otolaryngol Head Neck Surg. 2014; 3: 252-258

12. Ulku Han, Yucel A bitter. Osteoma of the mastoid region. Kulak Burun Bogaz Uygulamaları. 2013; 1(3):135-138

13. Cheng J, Garcia R, Smouha E. Mastoid osteoma: A case report and review of the literature. Ear Nose Throat J. 2013; 92(3):7-9

14. Güngör A, Cincik H, Poyrazoglu E, Saglam O, Candan H. Mastoid osteomas: report of two cases. Otol Neurotol. 2004; 25(2):95-7

15. Shindo A, Honda C, Baba Y, Takashima S, Nagano T. [Giant osteoma of thetemporal bone with otitis media: a case study]. No Shinkei Geka. 2000;28(3):281-6

16. Park SJ, Kim YH. A case of giant osteoma developed from the mastoid cortical bone. Korean J Audiol. 2012; 16(2):95-8.

How to cite this article/Bu makaleye atıf için:

Şahin C. [Mastoid Osteoma: A Case Report]. Acta Med. Alanya 2018;2(1): 49-51. Turkish. DOI: $10.30565 /$ medalanya.332231 